\title{
AVALIAÇÃO DE PERDAS DE MATÉRIAS PRIMAS: UMA PROPOSTA PARA MELHORIA NO PROCESSO DE UMA PANIFICADORA
}

\author{
RAW MATERIAL LOSS EVALUATION: A PROPOSAL TO IMPROVE A BAKERY PROCESS \\ Flavio Lucio Santos de Carvalho ${ }^{1^{*}}$ \& Clério Pereira Leite Junior ${ }^{2}$ \\ 12 Centro Universitário Salesiano - Unisales. \\ 1* fcarvalho@salesiano.br ${ }^{2}$ cleriop@ outlook.com.br
}

\section{ARTIGO INFO.}

\section{Recebido em: 21.10.2021}

Aprovado em: 21.12.2021

Disponibilizado em: 07.02.2022

\section{Palavras-ChaVe:}

VSM; Processos; Melhoria; Eficiência.

\section{KEYWORDS:}

VSM; Processe; Improvement; Efficiency.

*Autor Correspondente: Carvalho, F. L. S., de.

\section{RESUMO}

A competitividade acentuada entre as empresas do mercado faz com que as organizações busquem cada vez formas mais eficientes de aumentar a sua produtividade e minimizar o potencial de desperdícios dos seus recursos. Assim se torna fundamental o conhecimento de todas as atividades que agregam ou não valor ao processo e ao produto. Tem-se como uma das formas fundamentais para a melhoria dos processos e aumento do faturamento, a eliminação ou a redução dos desperdícios de recursos. Dessa forma, o atual trabalho mostra em seu objetivo sendo uma sugestão de proposta para melhoria do processo produtivo de uma panificadora situada em uma cidade da região norte do estado do Estado do Espirito Santo. Para tal êxito na pesquisa, foram coletados diversos dados dos processos produção da empresa como produção mensal, consumo de recursos e custos associados a produção. Posteriormente, a aplicação das ferramentas VSM e o Diagrama de Causa e Efeito que propiciaram uma melhor analise do processo e obtendo diagnostico da real e atual situação para a visualização e quantificação da mesma. Por fim, a proposta de sugestão para a melhoria do processo foi realizada visando a diminuição do consumo de trigo, recurso definido como de maior representatividade durante o processo produtivo, e uma melhor eficiência no processo como um todo.

\begin{abstract}
The increased competitiveness among the companies in the market causes organizations to increasingly seek ways to increase their productivity and minimize the potential for waste of their resources. Thereby it becomes fundamental knowledge of all the activities that add or not value the process and the product. One of the fundamental ways to improve processes and increase the revenues is the elimination or reduction of waste of resources. In this way, the present work shows its objective being a suggestion of proposal for improvement of the productive process of a bakery located in a city of the northern region of Espirito Santo State. To achieve this success in the research, several data were collected from the company's production processes such as monthly production, consumption of resources and costs associated with production. Subsequently, the application of the VSM tools and the Cause and Effect Diagram allowed for a better analysis of the process and obtaining a diagnosis of the real and current situation for the visualization and quantification of the same. Finally, the suggestion proposal for the improvement of the process was carried out aiming at reducing the consumption of wheat, a resource defined as being more representative during the production process, and a better efficiency in the process.
\end{abstract}




\section{INTRODUÇÃO}

Atualmente, é grande a exigência do cliente por um serviço de qualidade e com um preço acessível, portanto, isso tem sido um importante fator de gestão e competitividade no ambiente de mercado das organizações. Várias empresas têm buscado formas de se diferenciar e obter vantagem diante da concorrência, agregando valor aos seus produtos e processos internos para progressivamente seja possível elevar suas receitas e minimizar seus custos. Com isso se faz necessário: elevar o grau de qualidade e de produtividade sem que consequentemente, haja aumento das despesas inerentes aos processos de produção de forma proporcional. Diante deste cenário, existe uma dificuldade relacionada às aplicações das ferramentas e conceitos que possam facilitar o alcance das vantagens nos produtos e processos em uma empresa. Assim, as técnicas e ferramentas se apresentam bastante uteis e com resultados satisfatórios tanto em processos quanto em produtos.

A aplicação e utilização de tais conceitos e ferramentas de processos e da qualidade, quando aplicados de forma correta, tem por objetivo buscar melhorias nos processos para que haja aumento da produtividade de forma eficiente e totalmente focada nos processos e produtos de uma organização. Assim, é de suma importância a captação dos dados relacionados aos processos e analisá-los para a obtenção de informações que possibilitem a tomada de decisões mais assertivas visando a melhoria dos processos. Nessa pesquisa, foi realizada a análise de um dos processos de uma dada panificadora de pequeno porte onde nesta analise foram utilizadas ferramentas da qualidade e através das análises das mesmas propõem-se identificar falhas durante o processo produtivo.

O segmento de panificação apresenta grande destaque devido ao seu faturamento, de acordo com a Associação Brasileira de Indústrias de Panificação (ABIP 2016), o índice apontado no ano de 2016 foi de $\mathrm{R} \$ 87,24$ bilhões, embora a taxa de crescimento vem apresentando quedas conforme os anos, o direcionamento e expectativa para o setor ainda é de crescente faturamento de forma gradual sendo notório a expansão do faturamento durante os anos, saltando de $\mathrm{R} \$$ 39,61 bilhões em 2007 para R \$ 87,24 bilhões em 2016 conforme o Gráfico 1 abaixo, evidenciando a presença forte e a essencial importância da atividade industrial de panificação na economia brasileira.

Gráfico 1. Crescimento Faturamento em relação aos anos

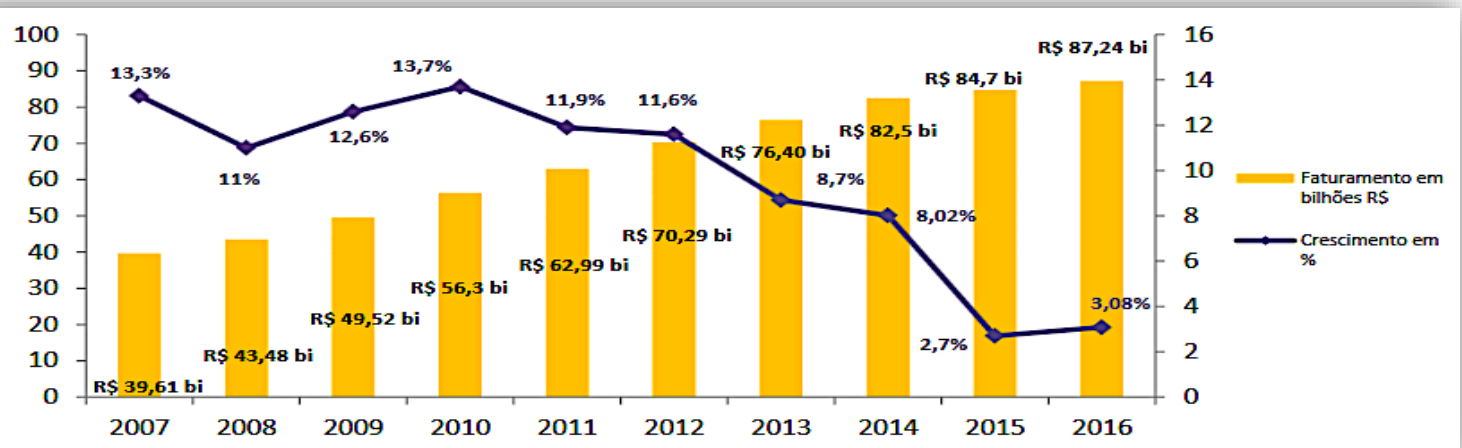

Fonte: Instituto Tecnológico de Panificação e Confeitaria citado por Associação Brasileira da Indústria de Panificação e Confeitaria, 2017. 

processo de uma panificadora. Brazilian Journal of Production Engineering, 8(2), 37-61.

O cenário competitivo atual faz com que as empresas busquem continuamente a melhoria e a eficiência dos processos de produção uma vez que influenciam e estão associados diretamente no faturamento das empresas. Assim, diversas organizações estão enfrentando diversas modificações substanciais, (como por exemplo a forma de relacionamento entre fornecedores e o sistema de produção e a influência desses fatores na satisfação do cliente final) na forma de disponibilizar seus produtos aos seus potenciais consumidores. A tendência é a pratica de aplicação e utilização de técnicas de melhoria contínua e de otimização em seus processos e produtos para aprimorar e alavancar os resultados do processo na busca da eliminação dos refugos e desperdícios existentes em todo o processo (Brito \& Dacol, 2008; Amorim \& Rocha, 2012).

Logo, justifica-se o atual estudo, uma vez que se pode analisar, apontar e mensurar as fases do processo que tem a propensão de oferecer ou aqueles que já oferecem a formação de desperdícios durante o processo produtivo, evidenciando a carência e a dificuldade da empresa em maximizar a utilização dos seus recursos e em aumentar a eficiência dos seus processos em razão da sua matéria prima ordenando toda a utilização dos recursos existentes com a real necessidade e eficiência final do processo, assim se abre a oportunidade para a possibilidade de propostas de melhorias e a minimização dos efeitos que impactam negativamente o processo.

A empresa analisada neste projeto de pesquisa, apresenta-se com relativas dificuldades quanto a contenção de matérias primas utilizadas na produção. O problema é constatado, principalmente, durante o manuseio das matérias primas pelos funcionários que se encontram à frente do processo produtivo. Assim, observa-se nesta etapa diversas falhas na produção ressaltando um elevado índice de desperdícios de materiais e outros recursos durante o processo produtivo, mesmo com faturamento elevado em função das vendas.

Observando e analisando as variáveis que influenciam no processo produtivo será possível a identificação e a diminuição das perdas e desperdícios da quantidade de Matérias Primas utilizados na produção de determinado produto, consequentemente, elevando a eficiência do processo para o produto pré-definido.

Portanto, tem-se como objetivo geral a avaliação das perdas de matérias primas nos processos propondo melhorias com a obtenção da minimização dos possíveis desperdícios das mesmas existentes, possibilitando então, a elevação da eficiência do processo de produção de uma empresa de pequeno porte, no setor de panificação. Deste podem-se destacar: elaborar referencial teórico acerca do tema de pesquisa; analisar e acompanhar todo processo produtivo nos meses de Junho à Outubro do ano de 2018; aplicar o Diagrama de Ishikawa e o VSM nos dados obtidos e propor melhoria no processo tendo em visa a minimização das perdas.

\section{REFERENCIAL TEÓRICO}

\subsection{As Contribuições de Henry Ford para a Indústria}

Atualmente não há possibilidades de separar nome de Henry Ford das linhas de montagem móvel. Ford sustentava que a sua produção não deveria sofrer diversificações e cada trabalhador seria responsável pela sua única tarefa para que pudesse aproveitar a maior eficiência do 

processo de uma panificadora. Brazilian Journal of Production Engineering, 8(2), 37-61.

funcionário de formas totalmente padronizadas com trabalho especializado focado apenas na sua tarefa. (Ohno, 1997; Maximiano, 2011).

A ideologia de Ford proporciona a considerável redução dos custos, aumentando, também, a qualidade dos produtos. Ao considerar neste instante apenas o sistema produtivo antigo e artesanal, uma máquina era capaz de realizar diversas atividades simultaneamente, entretanto com muitas revisões e paradas de produção, sendo necessário grande dispêndio de tempo do trabalhador e como resultado a severa diminuição da produtividade do trabalhador.

Henry Ford ao idealizar o sistema de produção em massa traz a drástica redução do tempo para preparo das máquinas, pois, nesse conceito, as maquinas realizavam somente uma tarefa e apenas essa para a função que assim estava designada. Com a pretensão de aumentar toda a eficiência do processo, Ford distribuiu suas máquinas de forma sequenciada e enfileiradas, onde, as etapas de fabricação eram subsequentes e seguia para a próxima etapa do processo uma por vez resultando no que chamamos de linhas de produção (Liker, 2005).

Alguns pontos significativos do sistema em produção proposto por Ford podem ser identificados sendo eles: Elevado grau de especialização do trabalhador, padronização das peças e a separação das atividades de trabalho. Por outro lado, era raro ou impossível a identificação em sugestões de melhoria continua e não havia qualquer responsável pela a iniciativa de proposta para a mesma do sistema produtivo de Ford. Consequentemente, sendo obsoleto com o passar dos anos. Era evidente a aceleração da produção e o menos custos unitário devido ao alto volume produzido, porem este sistema era consideravelmente inflexível. Schappo (2007) afirma as condições de inutilidade da filosofia de produção em massa, sendo elas:

- Grandes níveis de estoques;

- Alto valor de capital sem uso;

- Mão-de-Obra qualificada;

- Nível mínimo de flexibilidade.

\subsection{A CRIAÇÃO DO SISTEMA TOYOTA}

Também conhecido como o percursor da revolução industrial japonesa, Sakichi Toyoda, deu início a história da Toyota e de seu sistema de produção. Como forte atividade da indústria japonesa, a tecelagem apresentava importante papel na economia do Japão e embasado neste critério, Toyoda deu início a uma fábrica de teares com maior eficiência e com preços mais acessíveis. Toyoda deu um grande passo na eficiente dos teares, cada um tinha a competência de parar o andamento se caso fosse observado um fio rompido, assim, essa técnica é chamada autonomação (ou apenas automação), que viabilizava ao trabalhador desenvolver outras atividades (Liker, 2005).

Após realizar uma viagem para os Estados Unidos Sakichi Toyoda retornou com a pretensão de outorgar seu filho, Kiichiro Toyoda, a missão de planejar e construir uma indústria de carros pois no futuro os automóveis seriam os produtos que estariam em destaque e por conta do Segundo Conflito Mundial, a procura por caminhões no Japão estava crescente. Visto que o

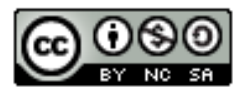



processo de uma panificadora. Brazilian Journal of Production Engineering, 8(2), 37-61.

Japão estava com grande necessidade de reconstruir o país totalmente destruído pela guerra, os americanos decidem apoiar a primeira fábrica a Toyota Motor Company.

Taiichi Ohno ganhou destaque ao migrar das linhas têxteis para a linha automobilística, tendo então, o total apoio de Eiji Toyoda (Na época presidente da Toyota Motor Company), em 1950 em visita as linhas de produção das fabricas da Ford nos Estados Unidos, Taiichi não encontrou mudanças significativas, ainda havia o padrão de linhas de produção em massa durante a manufatura, inúmeras máquinas em atividade gerando estoques incontáveis, ocultando diversas falhas tanto nos produtos como nos processos, ainda, com pouca ou nenhuma automação (Ohno, 1997).

Em 1970 com a crise do petróleo, a Toyota se coloca em um patamar acima de outras montadoras, várias empresas foram atingidas com os seus elevados custos, de todo modo, a Toyota consegue driblar essa situação e obter rendimentos com expressões maiores do que outros montadores (Schappo, 2007). Mas o diferencial da Toyota encontra-se na estruturação do próprio sistema produtivo no qual sempre irá priorizar a melhoria continua dos processos eliminando os gastos desnecessários, o chamado sistema de Produção Enxuta, ou Lean Production. (Ohno, 1997; Maximiano, 2011)

Ohno (1997) mostra que a fundamentação do Sistema Toyota de Produção é a absoluta eliminação do desperdício sendo constituídos por dois pilares:

- Just in time (JIT);

- Autonomação (Automação) ou Jidoka;

A autonomação ou automação, em poucas palavras, é a delegação da inteligência e tarefas humanas para a máquina. (Ohno, 1997).

O Just in time (JIT) é um sistema objetivo e procura atender a demanda de insumos de forma imediata para que não haja desperdícios e nem possa gerar estoques (Ohno, 1997). Moreira (2011) aponta, o JIT opera em um sistema nomeado "puxado". A explicação desse conceito não é de difícil compreensão, sempre se dará início no cliente ou na última estação de trabalho e logo é considerado todo o sistema atrás desse inicial. Para cada etapa de operação é requisitado à estação que está próxima o quanto será e o tipo de recurso que será utilizado para aquela etapa. Para cada estação é necessário que os itens sejam requisitados, caso isso não ocorra os itens não serão produzidos consequentemente não irá gerar estoques desnecessários aumentando os custos significativamente. Para produção ser puxada, utiliza-se a ferramenta indispensável na filosofia JIT, chamada Kanban que é capaz de ser compreendido como o lançamento de aprovação de produção de itens necessários.

O Kanban é caracterizado como uma ferramenta visual que auxilia o controle e movimentação de materiais entre estações de trabalho, a ideia é mandar sinais conforme a necessidade e priorização da estação para que os operários possam iniciar tarefas específicas. (Moreira, 2011). 


\subsection{Os Principios do Sistema Toyota de Produção}

Segundo Liker (2005) e Shingo (1996), a Produção Enxuta possui sete formas de perdas e ou desperdícios:

- Superprodução: é a perda proporcionada pela produção, geralmente fora do tempo e/ou acima da necessidade geralmente está ligada ao processo de produção;

- Tempo de espera: Dispêndio de tempo pela demora de recursos que ainda não estão disponíveis que também pode gerar em ociosidade dos operadores;

- Transporte: Transportes desnecessários;

- Processamento: Apresentas as variáveis que possam ocasionar o andamento de forma errônea de algum produto e/ou serviço, geralmente ligada ao processo de produção.

- Estoque: Apresenta as variáveis que os custos dos estoques e de difícil percepção devido ao alto volume dos estoques;

- Dispêndios de movimentação: Engloba a movimentação dos operados a procura de recursos para a produção;

- Dispêndios no projeto de produtos com falhas: Relaciona-se com a demanda de retrabalho devido às diversas falhas no projeto e elaboração dos produtos.

\subsection{Gestão da Qualidade}

Carpinetti (2012) mostra que, a gestão da qualidade é atualmente fator estratégico para proporcionar uma melhoria da produtividade e da qualidade. Tal fator também é fundamental para promover a satisfação dos clientes e promover um bom olhar da empresa perante a sociedade em geral, consequentemente, elevando os padrões da empresa para se alinha ao mercado interno e externo.

A combinação de particularidades de determinado produto ou serviço quando se relacionam com a engenharia, produção, marketing, manutenção podem trazer a definição da qualidade das quais podem atender ou não às expectativas do cliente (Feigenbaum, 1994).

Crosby (1990) diz que, o Sistema pelo qual assegura que as atividades pré-determinadas possam ocorrer como o que já estava projetado, assim, a gestão da qualidade se enquadra na finalidade de prever, prevenir e controlar problemas que possam vir a ocorrer.

É notória, a clareza da importância da qualidade nos processos e nos produtos para o qual atenderá o que o cliente espera promovendo a satisfação dos mesmos e das empresas.

\subsection{Ferramentas da Qualidade}

As ferramentas de qualidade são métodos utilizados para propor respostas aos problemas que comprometem o desempenho das práticas de trabalho a fim de que sejam mitigados os mesmos (Malik \& Schiesari, 1998).

Além de organizar os problemas de acordo com o grau de importância, as ferramentas propiciam o auxílio às identificações das causas e problemas que afetam todo o processo produtivo, ainda, auxiliam nas tomadas de decisões e ações relacionadas a eliminação das fontes associadas aos mesmos, resultando na eficiência do processo, aumentando a qualidade e a

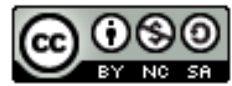



processo de uma panificadora. Brazilian Journal of Production Engineering, 8(2), 37-61.

produtividade (Werkema, 2006; Gadelha \& Morais, 2015). Embora existam atualmente inúmeras ferramentas e métodos, destaca-se a aplicação do Diagrama de Ishikawa ou de Causa e Efeito.

\subsubsection{Diagrama de causa e efeito}

Toledo et al. (2014) define, o Diagrama de Ishikawa sendo a ilustração dos dados coletados sobre um problema determinado que auxiliam com a identificação de quais são as características que necessitam ser trabalhadas a analisadas.

Geralmente, nas indústrias, os problemas nascem normalmente em seis áreas, denominadas como os seis "M": materiais, mão-de-obra, máquinas, métodos, meio ambiente e medidas, partindo daí damos o nome de espinha ou ramos (Peinado \& Graeml, 2007).

As variáveis que influenciam são destacadas em cada uma das espinhas, sempre relacionando a causa com a espinha, assim montamos o diagrama e pode-se analisar com uma visão sistêmica ordenada com todas as influências sobre uma determinada causa (Kirchner, 2009).

A identificação das variáveis e das possíveis interferências é realizada normalmente por uma ferramenta denominada "brainstorming", que tem por finalidade o máximo de geração de pensamentos ou ideia de um determinado assunto ou causa sendo dentro de um período estipulado. (Peinado \& Graeml, 2007).

\subsubsection{A Melhoria Contínua}

A melhoria contínua define-se sendo um incessante e permanente processo de melhoramento e aprimoramento de produtos e processos. É um processo participativo e cíclico, ou seja, procura sempre o melhor através de avaliações de resultados obtidos pela averiguação do processo com uma ação de melhora sobre um determinado objeto de estudo, no qual se podem sugerir novas práticas de aperfeiçoamentos tornando o dessa forma o processo em ciclo virtuoso de melhoria (Carpinetti, 2012).

Para Peinado e Graeml (2007) A melhoria contínua é fundamentada na filosofia japonesa denominada Kaizen, que em síntese, busca de modo contínuo a melhoria de todas as ações que englobam uma organização, tornando-as gradativamente mais eficientes e usuais, entretanto, é necessário a criação de uma cultura de aperfeiçoamento continua em toda as áreas da empresa. A forma mais renomada e conhecida, usual e genérica é o ciclo PDCA, pela sua simplicidade e facilidade o modelo é adotado em inúmeras organizações e proporciona a facilidade na compreensão das ações.

\subsubsection{Folhas de Verificação}

Para Vieira (1999) A folha de verificação é uma ferramenta para registro de dados onde o seu uso visa flexibilizar a coleta de dados. Kume (1993) mostra que a necessidade de coletar dados se faz necessária para diagnosticar e esclarecer os fatos a serem analisados.

Para tal, é importante estabelecer toda a conexão dos dados com o que se deseja analisar bem como a sua objetividade. Assim os registros dos dados podem possibilitar o melhor entendimento da realidade e uma direta interpretação da situação, desenvolvendo a diminuir erros. Segundo Werkema (1995) uma folha de verificação é um formulário no qual os itens a 

processo de uma panificadora. Brazilian Journal of Production Engineering, 8(2), 37-61.

serem considerados já estão prontos, facilitando a coleta e o registro dos dados, de forma a auxiliar para otimizar a posterior análise.

Para Carvalho (2012) as folhas de verificação são representações gráficas que mensuram processos e tarefas planejadas, tanto em andamento quanto aquelas que devem ser executadas.

Werkema (1995) define algumas direções para as folhas de verificação mais empregadas de acordo com a sua devida aplicação são:

- Identificação e Controle de um processo produtivo;

- Para realizar classificações;

- Verificar a Localização de defeitos;

- Identificação e mensuração de causas de defeitos.

A folha de Verificação pode ser classificada como uma das mais simples, habitual e comum ferramenta sendo eficiente para analisar o desenvolvimento de atividades ao longo de um processo.

\subsection{Mapeamento de Fluxo de Valor - VSM}

Para Womack e Jones (1998), desperdícios e perdas devem ser entendidos como falhas que necessitam de algum tipo de correção. Por vezes estas falhas estão associadas às diversas atividades dentro de um processo produtivo, mas que nem sempre vão estar visíveis. Ainda para o autor, a ideia de cadeia de valor de um produto, ou seja, as etapas e atividades na fabricação de um produto que possam agregam valor para o cliente é considerado desde os fornecedores até o momento do pós-venda. Por esta razão, apenas a aplicação do conceito de uma produção enxuta não é suficiente para melhorar os processos de uma empresa, tal conceito deve ser estendido a todas as áreas e etapas envolvidas no processo.

Neste sentido, inúmeras ferramentas e técnicas aprimoradas estão disponíveis para ajudar e auxiliar na identificação e quantificação nos pontos chaves para a agregação de valor no processo e posteriormente a implementação do conceito de produção enxuta disseminada de forma total no processo. O Mapeamento do Fluxo de Valor (VSM) é uma ferramenta significativa e importante nesta quantificação e consiste numa visualização macro dos fluxos de materiais e informações necessárias no processo produtivo (Rother \& Shock, 1999).

Cadioli e Perlatto (2008) deixa evidente que o fluxo de valor é trilho por onde o produto deve seguir, isto é, processo de transformação da matéria em produto acabado e disponibilizado ao cliente final. De acordo com essa afirmação, Womack e Jones (2004), dizem que, percorrer esse trajeto surgirão atividades que agregarão ou não valor ao produto e, devido a isso, todas as áreas envolvidas no processo produtivo deve possuir completo conhecimento de todas as etapas e/ou tarefas visando a eliminação ou a diminuição das fases que não agregam valor ao produto.

Assim, se assume o VSM como um ferramental de grande impacto para o sistema produtivo trazendo para as organizações uma macro visão de todas as fases do processo e possibilitando a interação entre as áreas de forma a flexibilizar as relações para um melhor planejamento dos processos direcionando o mesmo a eficiência de produtividade e minimização dos custos (Rother \& Shock, 1999). 


\subsection{Processos}

Entende-se processo como um conjunto de atividades determinadas e que estão organizadas para transformar os recursos e insumos (inputs) em saídas (output) para os consumidores finais. Causam efeitos e que também provocam o surgimento de necessidades de gerenciamento e medição da sua execução (Carvalho \& Paladini, 2005).

Se baseiam em um sistema de produção que é capaz de transformar matérias primas e demais recursos em saídas (sejam elas produtos ou serviços) (Gaither \& Frazier, 2002). Os processos devem seguir um padrão de atividades muito bem planejadas para que sempre seja observada a constância e sequência desejadas durante a execução do mesmo, também, não afete a qualidade do produto final. Para que o êxito do processo juntamente com o alcance da qualidade almejada do produto final, o gestor de processo deve assumir a completa responsabilidade de acompanhar os processos produtivos desde as entradas (inputs) até as saídas (outputs) do sistema para se avaliar toda a eficiência do processo. (Alvarez, 2016).

\subsection{Perdas}

Não excluindo os desperdícios apontados e apresentados no tópico 2.2 do presente estudo, Bornia (1995) afirma, há possibilidade de se encontrar outros tipos de perdas envolvendo os recursos disponíveis, sendo estas perdas, o alto grau de desperdício de recursos que foram gastas ou consumidas de maneira anormal ou além do necessário. Por vezes, esse fator de perda geralmente está ligado a outros fatores, podemos exemplificar: Ferramentas ou equipamentos sem regulagem; Falta de interesse no trabalho pelos colaboradores; Equipamentos ou ferramentas defasadas; Nível de qualidade dos materiais e/ou matérias primas; ambiente de trabalho; dentre outros.

Ainda neste sentido, todo e qualquer recurso utilizado na produção ou no processamento de determinado bem (seja produto ou serviço) consumido acima do necessário pode ser considerado uma perda de recursos ou de matérias primas, tal perda tem consequência diretamente no custo e/ou no faturamento de determinada organização (Santos, 2016).

\section{METODOLOGIA}

O atual trabalho mostra, em relação aos seus objetivos, como uma pesquisa exploratória, descritiva e aplicada, devido à busca por uma maior familiaridade com o cenário da empresa e com os conhecimentos científicos, na qual foi descrito todo o problema, em relação a qualidade e as características que foram observadas, como objetivo propor melhorias no processo de fabricação de uma panificadora. Em relação aos métodos aplicados, caracteriza-se como um estudo bibliográfico e estudo de caso. A sustentação teórica será conquistada por pesquisas de estudos já feitos em livros, revistas, sites e em trabalhos já desenvolvidos por outros estudantes, pesquisadores e partes envolvidas no ramo sobre o mesmo tema proposto por este trabalho realizando-se uma sondagem e análises do que está relacionado e do que já tem fornecido, por outros meios, sobre a proposta de pesquisa.

A pesquisa de campo evidencia uma abordagem qualitativa e quantitativa. Caracteriza-se como qualitativa, pois busca descrever todo contexto do problema de pesquisa, com o auxílio de observações e descrições. A geração de dados irá propiciar as devidas avaliações, porém, não 
se pode obter com precisão e assertividades as decisões necessárias para a avaliação do problema enfatizado, abre-se assim espaço para as análises quantitativas.

Neste estudo, a amostra pesquisa é de posse de uma panificadora de tradição e história na região norte do Espirito Santo de pequeno porte, localizada no município de Linhares e que possui quatro filiais espalhadas pela região norte do estado. O foco principal do trabalho está voltado para o seu processo de produção devido a constatação do alto índice de consumo de matérias primas em uma dessas filiais, ainda, o estudo pode ser estendido a qualquer outra panificadora desde que haja as mesmas premissas de processo produtivo. Os dados da produção da empresa foram fornecidos pelos proprietários da empresa e ainda por meio de observação participante no processo produtivo, com relatórios e históricos das atividades empregadas do processo.

Para o processo de coleta dos dados foram feitas análises de relatórios de quantidade de itens produzidos, quantidade de matérias primas adquiridas e consumidas, acompanhamento presencial dos processos, entrevistas e outros dados coletados a partir da monitoração e melhor compreensão do processo. Inicialmente, foi realizada uma pesquisa para verificar e mapear a atual situação do processo produtivo na empresa em diversos pontos como: processo de fabricação; gerenciamento; equipe de trabalho; satisfação da equipe; matérias primas utilizadas juntamente com seus preços praticados e outras variáveis necessárias para a avaliação do processo. A Pesquisa buscou a verificação e analises de condições de não conformidades em algum ponto durante o processo de produção especificamente do pão francês devido a constatação do alto índice de consumo de matérias primas.

Nesse sentido, para contribuir com a diminuição do consumo de matéria prima na produção e aumentar a eficiência do processo, foram empregadas ferramentas da qualidade separadamente para cada caso. Assim, pôde-se dar maior ênfase para a aplicação do Diagrama de Causa e Efeito para identificar relações entre fatores que afetam o processo e na ferramenta de Mapeamento de Processos VSM que procura dar evidencia em todas as etapas do processo com uma visão macro, porém, não se exclui pequenas parcelas do processo que podem ser significativas possibilitando aplicação de outras ferramentas

\subsection{Objeto de Estudo}

A fundação da panificadora teve seu início no ano de 2009 como uma pequena unidade de comercio alimentício sem nenhum tipo de caracterização especifica, com o passar dos anos houve acréscimos na unidade surgindo a necessidade da migração definitiva para apenas a atividade de panificação que consequentemente foi necessária uma nova localização para a empresa, em seguida a história se encarregou na criação de um nome e padrões que se fixam até os dias atuais. No ano de 2013, já com três filiais conectadas com o mercado, houve uma grande mudança no cotidiano da panificadora, com a aquisição de novos maquinários e equipamentos que mudaram todo o processo de fabricação. A princípio, tal mudança alavancou a capacidade de produção influenciando no processo de fabricação dos produtos, com isso a panificadora promoveu a qualificação de todos os funcionários envolvidos na produção proporcionando a oferta de novos tipos de produtos para venda diária, principalmente na área de pequenos lanches, com o propósito da diversificação dos produtos ofertados, visando a fidelização de um maior número de clientes. 

processo de uma panificadora. Brazilian Journal of Production Engineering, 8(2), 37-61.

Atualmente a empresa é formada por 17 funcionários dentre padeiros, confeiteiros e auxiliares de panificação e atende uma parcela significativa de clientes mensais. Embora seja uma empresa de pequeno porte, é notório a força com que a empesa estabelece no mercado visto que está localizada em local estratégico da região e amplamente conhecida no bairro no qual está inserida e se destaca pela sua excelente forma de atendimento ao cliente, variedade de produtos e perfeito ambiente acolhedor.

\section{RESULTADOS E DISCUSSÃO}

\subsection{Descrição do Processo Produtivo}

A produção é dividida em: massas salgadas e massas doces que são utilizadas para a produção de produtos que possuam tal característica, entretanto, o maior percentual dessa massa é direcionado para a produção de pães. Dentre a massas salgadas que está destinada a produção de pães, ainda se subdivide em dois tipos sendo: pão francês e pão médio. Em contrapartida, a massa doce é utilizada para diversos produtos como: cremes, pães doces, bolos, biscoitos e diversos outros itens com a variação apenas na concentração de massa para a produção de cada um. A produção dos pães se dá inicialmente pelo processo da massa base dos que trata como princípio de acordo com o Figura 1 abaixo:

Figura 1. Fluxograma de processo estudado

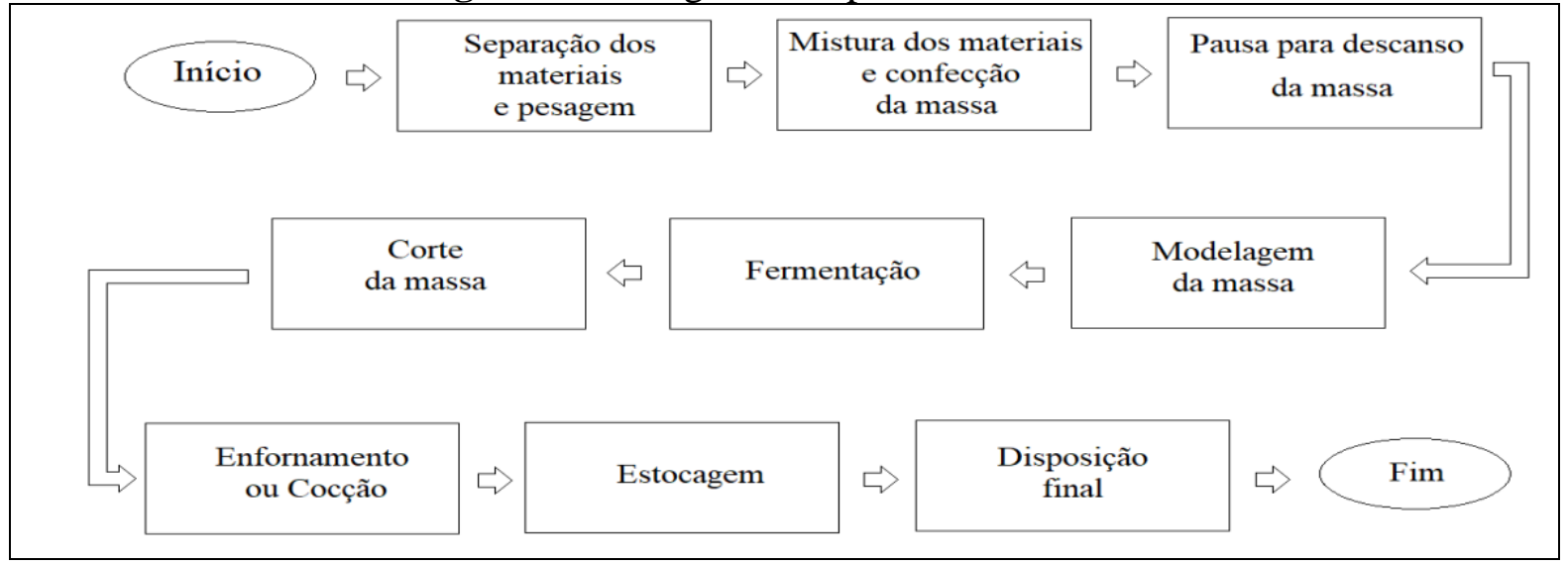

Fonte: Autores (2021).

A empresa não possui um histórico significativo quanto relacionado à produção dos pães de sal, o que foi constatado devido ao alto grau de consumo dos insumos necessários juntamente com a avaliação dos funcionários e proprietários, isto, após a observação de sempre apresentar a dificuldade em produzir a quantidade esperada para aquele dia e por vezes ser necessário a aquisição de mais matérias primas além do que já se possui, isto é, as fabricações dos pães de sal estavam saindo com custos mais elevados do que o previsto para o processo, onde este influencia diretamente no faturamento final esperado de cada quantidade produzida.

Para início de todo o processo, a primeira fase é a seleção e a separação de todos os itens necessários. Nesta etapa ocorre a compra mensal com a entrega diária dos materiais demandados, assim, a seleção e a quantidade de materiais são feitas de forma totalmente igualitária e conforme a proporção da quantidade de itens que serão produzidos no dia. Após essa etapa, ocorre a pesagem dos itens para a quantidade de itens que serão produzidos de forma total.

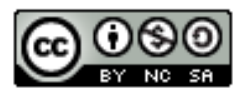



processo de uma panificadora. Brazilian Journal of Production Engineering, 8(2), 37-61.

Os próximos processos, Mistura dos materiais e confecção da massa, descanso da massa, Modelagem e Corte da massa

O processo de corte da massa, é realizado de forma manual com tamanhos mensurados pelos funcionários a frente do processo visando sempre um padrão, aqui não é definido nenhum tamanho padronizado, tudo é realizado conforme o entendimento das pessoas a frente do processo. Foi observado o descarte dos restos de cortes que não foram uteis e que ainda estão em bom estado para a utilização e não retornam ao processo produtivo, caracterizando um desperdício de produto semiacabado e futuramente desperdício de produto acabado impactando na receita e nos custos da empresa.

O processo de cocção acontece em fornos que são intermitentes até três vezes ao dia sendo relativo à quantidade de itens produzidos no dia, sendo necessário a utilização de gás encanado para o aquecimento dos mesmos.

\subsection{Apresentação e Análise dos Dados}

A realização da coleta de dados teve como objetivo identificar e mensurar como ocorre o consumo do trigo utilizado no processo produtivo, a sua aquisição e o seu devido consumo. $\mathrm{O}$ conhecimento de tais dados na empresa analisada pode proporcionar uma visão sistêmica de toda a execução da fabricação dos itens. Neste sentido, foi necessário a divisão dos dados em períodos quinzenais para a flexibilidade da análise dos dados, esta divisão foi realizada apenas para os períodos dos meses de maio a outubro, período em que o processo foi monitorado, e se restringindo há apenas estes meses.

Os dados coletados foram obtidos através de pesquisa dos históricos de consumo e aquisição bem como a sua aplicação do processo de produção. Ao analisar tais dados é evidente a ineficiência na utilização da matéria-prima para a produção de determinada quantidade de itens esperada. Os dados foram tratados nos Softwares Microsoft Excel e no Minitab onde foi realizado as aplicações necessárias para as devidas analises e a utilização as ferramentas propostas nesta pesquisa. Da mesma forma o Software Microsoft Visio foi de grande importância para o desenvolvimento da aplicação das ferramentas Diagrama de Ishikawa e o Mapeamento do Fluxo de Valor VSM.

\subsection{Análise dos Desperdícios de Matérias-Primas}

Para atingir a quantidade ideal ou esperada no processo, deve ser observado sempre as relações entre os recursos disponíveis e os parâmetros de produção empregados pois todos possuem direta correlação e interferência no processo. Logo, os recursos disponíveis devem ser amplamente observados e acompanhados com a visão de controlar ou eliminar todo e quaisquer que sejam as razões e/ou fontes de desperdício.

Considerando realizar apenas a análise do processo produtivo do pão francês visto que há o maior índice de vendas, a primeira etapa a ser feita é a identificação das matérias primas que são de maior importância dentro da produção dos mesmos e após realizar a verificação da possibilidade teórica dos desperdícios existentes durante a produção, para tal verificação foi oferecido pelos proprietários os dados particulares às compras e a aplicação das mesmas durante o período observado, tais dados foram utilizados juntamente com o monitoramento do processo. 

processo de uma panificadora. Brazilian Journal of Production Engineering, 8(2), 37-61.

A princípio tem-se como principal matéria-prima para produção a farinha de trigo, sendo esta a matriz para a mistura de outros ingredientes até a formação da massa. Abaixo (Tabela 1)) está a relação dos itens necessários para a produção de apenas uma unidade de pão, deve ser considerado que está sendo apresentado as médias dos valores dados, visto que a unidade não apresenta valores constantes.

Tabela 2. Representatividade dos Ingredientes

\begin{tabular}{c|c|c}
\hline Ingrediente & Percentual (\%) & Para um Pão de 45g \\
\hline Farinha de Trigo & $68 \%$ & 30,6 \\
Água & $27 \%$ & 12,15 \\
Sal & $1 \%$ & 0,495 \\
Fermento Biológico & $1 \%$ & 0,495 \\
Gordura & $2 \%$ & 0,9 \\
Melhorador de Farinha & $1 \%$ & 0,225 \\
\hline
\end{tabular}

Fonte: Adaptado da empresa pesquisada, 2018.

A tabela 1 apresenta que a maior participação na composição de um pão é formada pelo trigo com um percentual de $68 \%$ em sua fabricação. Para descobrir a representatividade do custo do trigo em relação aos demais itens os dados coletados em relação aos custos dos itens se apresentam na Tabela 2 a seguir.

Tabela 3. Custos dos Ingredientes

\begin{tabular}{c|c}
\hline \multicolumn{2}{c}{ Custos dos Ingrediente } \\
\hline Farinha de Trigo 50kg & $\mathrm{R} \$ 145,95$ \\
Sal 10kg & $\mathrm{R} \$ 72,00$ \\
Fermento Biológico 15kg & $\mathrm{R} \$ 32,25$ \\
Gordura 10kg & $\mathrm{R} \$ 46,25$ \\
Melhorador de Farinha 10kg & $\mathrm{R} \$ 31,25$ \\
\hline
\end{tabular}

Fonte: Adaptado da empresa pesquisada, 2018.

Observa-se pela tabela 2 os custos de acordo com a quantidade de matéria prima adquirida, na tabela mostra-se que o trigo apresenta a maior representatividade se comparado aos demais itens, logo, este será o item principal desta análise.

Embora grandes variabilidades no processo da produção do Pão Francês foram demonstradas, a produção da massa doce não sofre grandes perdas de insumos no processo de produção sendo necessário apenas ocasional e/ou pontuais aquisições de novos insumos de produção, contudo, sem grande necessidade de compra de altas quantidades e em curtos espaços de tempo. Neste sentido, destinou-se analisar as circunstancias e intervir apenas no processo de produção da massa salgada.

\subsubsection{Causas Identificadas para o Desperdício de Matéria Prima}

Ao ser aplicado o Diagrama de Ishikawa, se nota as causas que podem estar causando o alto índice de desperdício de trigo durante o processo. Assim, abaixo está evidenciado na Figura 2, o Diagrama quando aplicado juntamente com a observação de todo o processo de produção 

processo de uma panificadora. Brazilian Journal of Production Engineering, 8(2), 37-61.

Figura 2. Diagrama de Ishikawa

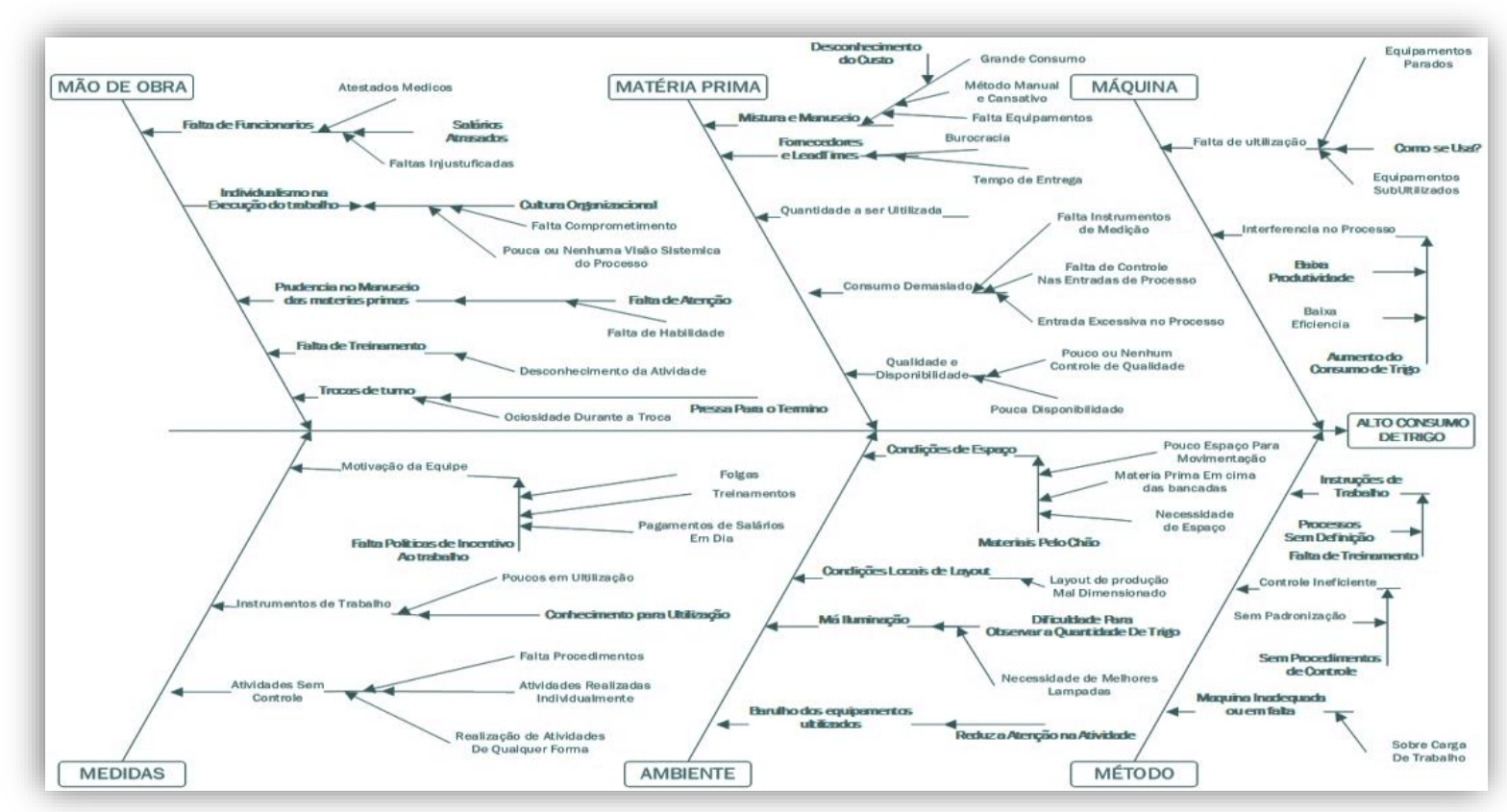

Fonte: Autores (2021).

De posse dessas informações, pode-se verificar de uma forma sistêmica as possíveis causas dos desperdícios. Porém, apenas a aplicação e analise dessa ferramenta não é suficiente para a total visão dos detalhes do processo, sendo necessário a verificação dos dados de consumo e de produção juntamente com a atenção presencial de todo processo.

Pode ser observado inúmeras causas que tem como consequência o efeito gerado, entretanto, será trabalhado apenas as causas relacionadas às matérias primas visto que de acordo com a Tabela 2 a maior representatividade dos custos está na matéria prima. Não se descarta que, para um melhor aprofundamento e a obtenção de melhores resultados, a análise e a atuação nas demais causas se faz necessária.

Ainda, considera-se a existência dos custos fixos que aumentam significativamente os custos e despesas no processo como por exemplo, custos de mão de obra e custos com alugueis, destinando-se a analise apenas para a variável de matéria prima.

\subsubsection{Análise do Mapeamento Fluxo de Valor do Estado Atual}

Ao ser aplicado o Mapeamento Fluxo de Valor, pode ser verificado e observado de forma macro o mapeamento e o comportamento de seus recursos durante o processo. Assim, abaixo está evidenciado VSM quando aplicado juntamente com a observação de todo o processo de produção. 

processo de uma panificadora. Brazilian Journal of Production Engineering, 8(2), 37-61.

Figura 3. Mapeamento do Fluxo de Valor do Estado Atual

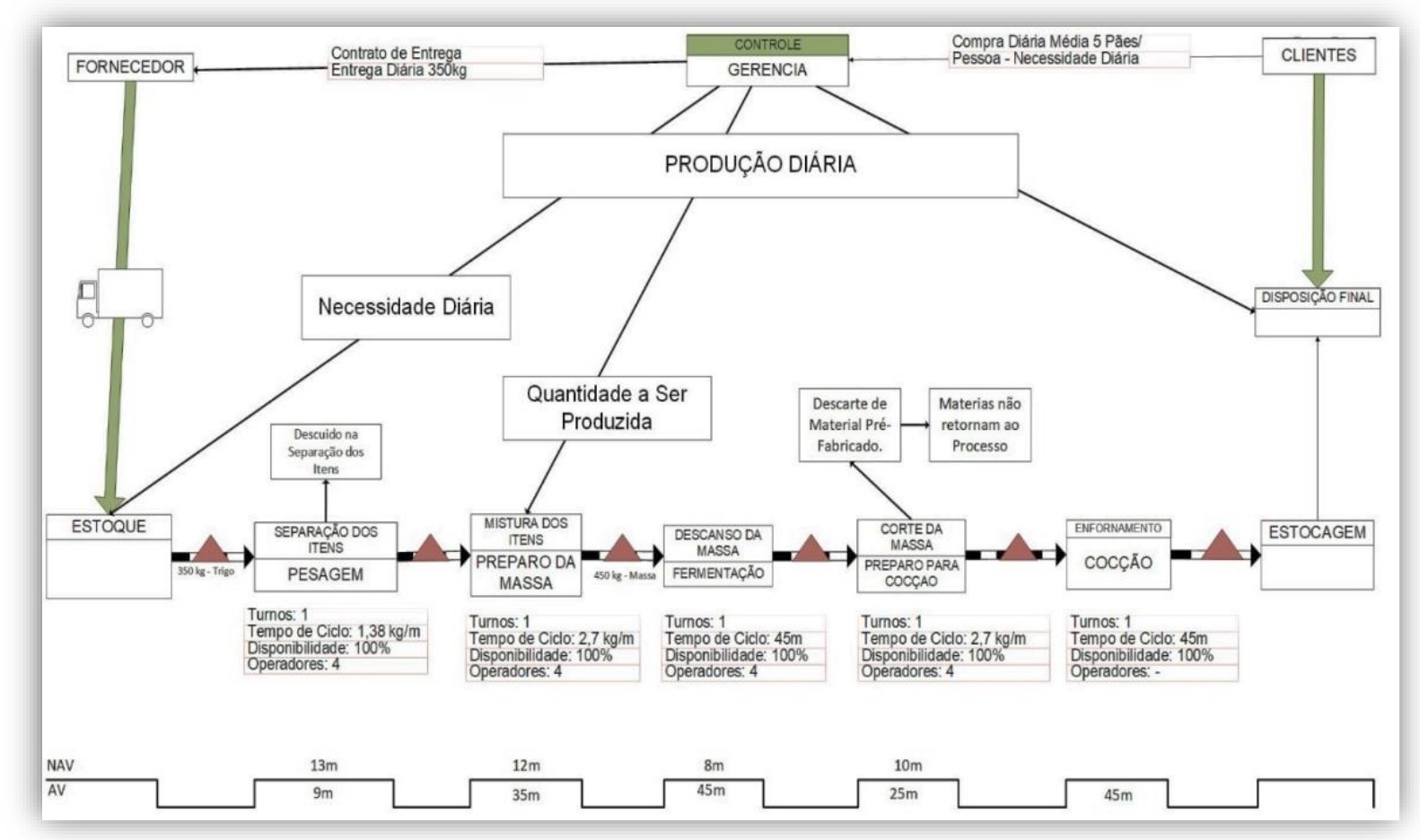

Fonte: Autores (2021).

A Figura 3 acima nos evidencia o estado atual que o processo se encontra e pela mesma está sendo observado que alguns pontos estão com gastos demasiados sendo especificamente as etapas de corte que parcela dos itens pré-fabricados são descartados nesta etapa não retornando ao processo e na etapa de Separação dos materiais onde a quantidade que está entrando do estoque não está sendo a mesma que está saindo. As Reutilizações dos itens da etapa de corte podem propiciar significativa evolução na quantidade produzida e/ou na redução dos custos. Em cada etapa do fluxo de valor espera-se um resultado mínimo para que a próxima etapa siga o processo.

É importante ressaltar que no atual processo os operados não seguem para a próxima etapa antes da atual ser realizada por completo, o que deixa o material pré-fabricado ocioso em certas etapas do processo proporcionando por consequência a elevação do tempo de fabricação do produto. Tal ociosidade também pode gerar perda deste material pré-fabricados visto que este é formado por matérias primas perecíveis e de fácil degradação caso isso ocorra, acarretará em atrasos para as etapas do processo subsequentes podendo gerar aumento do custo.

Da mesma forma, é importante observar a participação ativa de todos os funcionários em todas as etapas do processo sem que haja o adiantamento de qualquer etapa posterior durante o processo. Em cada etapa há pelo menos oito funcionários presentes no processo sendo os mesmos das etapas anteriores sendo, quatro padeiros e quatro auxiliares de panificação. $\mathrm{O}$ processo ainda mostra que não há a influência direta dos proprietários no processo, logo, não há um devido acompanhamento das etapas do processo. Este acompanhamento só é realizado no estoque; na etapa de mistura das matérias primas e na disposição final do produto, dessa forma, não se apresenta um controle efetivo sobre o processo produtivo o que pode ocasionar severas perdas de matéria prima. 

processo de uma panificadora. Brazilian Journal of Production Engineering, 8(2), 37-61.

\subsubsection{Análise da Produção e Consumo}

Para o entendimento do consumo da matéria prima de acordo com a produção, foi necessário o mapeamento dos itens produzidos diariamente, tal observação assim realizada através de documentos já registrados em posse dos proprietários, em outro momento, o acompanhamento do processo presencialmente pode facilitar o entendimento dos dados observados.

A Tabela 3 a seguir apresenta as quantidades produzidas no mês e no dia registrado, mostrando a coleta de dados registrada nos meses de maio a outubro, dessa forma a construção da base de dados ainda está em processo e se apresenta de forma parcial. Os dados fornecidos pela empresa foram tabelados juntamente com a análise do processo presencialmente, observa-se que os itens produzidos e não vendidos em determinado dia eram somados aos itens produzidos do próximo dia, o que causava desencontro entre os dados obtidos, porém, ao ser utilizado o Software Minitab é verificado que os dados seguiam uma distribuição normal. Dessa forma, se obteve a média de produção diária de acordo com a quantidade de trigo adquirida diariamente e a sua respectiva venda para a melhor analise e conclusões necessárias.

Tabela 4. Produção e Consumo de trigo (continua)

\begin{tabular}{c|c|c|c|c}
\hline \multicolumn{5}{c}{ Soma Compras (KG) } \\
\hline \multicolumn{2}{c|}{ Mês } & $\begin{array}{c}\text { Quantidade Comprada } \\
(\mathbf{k g})\end{array}$ & $\begin{array}{c}\text { Quantidade Consumida } \\
(\mathbf{k g})\end{array}$ & $\begin{array}{c}\text { Quantidade Produzida } \\
(\mathbf{k g})\end{array}$ \\
\hline \multirow{2}{*}{ Maio } & $1^{\circ}$ Quinzena & 5350 & 4216,0 & 4170,9 \\
& $2^{\circ}$ Quinzena & 5795 & 4617,0 & 4570,8 \\
\hline \multirow{2}{*}{ Junho } & $1^{\circ}$ Quinzena & 5405 & 4116,0 & 4074,8 \\
& $2^{\circ}$ Quinzena & 5480 & 4121,0 & 4079,8 \\
\hline \multirow{2}{*}{ Julho } & $1^{\circ}$ Quinzena & 5410 & 4207,0 & 4164,9 \\
& $2^{\circ}$ Quinzena & 5745 & 4514,0 & 4468,9 \\
\hline \multirow{2}{*}{ Agosto } & $1^{\circ}$ Quinzena & 5335 & 4188,0 & 4031,6 \\
& $2^{\circ}$ Quinzena & 5795 & 4699,0 & 4283,7 \\
\hline \multirow{2}{*}{ Setembro } & $1^{\circ}$ Quinzena & 5450 & 4404,0 & 4266,5 \\
& $2^{\circ}$ Quinzena & 5390 & 4621,0 & 4476,6 \\
\hline \multirow{2}{*}{ Outubro } & $1^{\circ}$ Quinzena & 5250 & 4504,0 & 4141,5 \\
& $2^{\circ}$ Quinzena & 5600 & 4935,0 & 4494,7 \\
\hline
\end{tabular}

Fonte: Adaptado da empresa pesquisada, 2018.

\subsubsection{Análise dos custos do trigo}

A Tabela 4 a seguir mostra os custos de aquisição do trigo. A mesma é dividida de forma que os custos de cada mês sejam contabilizados e dispostos na forma mensal.

Tabela 5. Aquisições de Trigo ao Mês

\begin{tabular}{c|c|c|c}
\hline \multicolumn{4}{c}{ Compra total de Trigo } \\
\hline Mês & Soma compras (kg) & Preços $(\mathbf{R} \$)$ & Total $($ preço/kg) \\
\hline Maio & 11145 & $\mathrm{R} \$ 145,95$ & $\mathrm{R} \$ 32.532,26$ \\
\hline Junho & 10885 & $\mathrm{R} \$ 145,95$ & $\mathrm{R} \$ 31.773,32$ \\
\hline Julho & 11155 & $\mathrm{R} \$ 145,95$ & $\mathrm{R} \$ 32.561,45$ \\
\hline Agosto & 11130 & $\mathrm{R} \$ 145,95$ & $\mathrm{R} \$ 32.488,47$ \\
\hline Setembro & 10840 & $\mathrm{R} \$ 145,95$ & $\mathrm{R} \$ 31.641,96$ \\
\hline Outubro & 10850 & $\mathrm{R} \$ 145,95$ & $\mathrm{R} \$ 31.671,15$ \\
\hline Total & $\mathbf{6 6 0 0 5}$ & $\mathrm{R} \$ \mathbf{1 4 5 , 9 5}$ & $\mathbf{R} \$ \mathbf{1 9 2 . 6 6 8 , 6 0}$ \\
\hline
\end{tabular}

Fonte: Adaptado da empresa pesquisada, 2018. 

processo de uma panificadora. Brazilian Journal of Production Engineering, 8(2), 37-61.

$\mathrm{Na}$ Tabela 4 mostra-se a analise realizada no período de maio a outubro e visualiza-se o alto índice de custos para o trigo, item predominante na fabricação dos produtos. Neste sentido, não será considerado outros fatores que podem aumentar o custo de produção, a analise detém-se apenas no custo bruto de aquisição do trigo.

\subsubsection{Utilização da Folha de Verificação}

Para obter resultados mais precisos acerca do consumo de matéria prima no processo, foi considerado e já mencionado no item 4.3.1 desta pesquisa, o direcionamento da causa que está sendo analisada. Assim, a aplicação da folha de verificação pode mostrar a atual realidade do processo relacionada a entrada e saída do trigo em cada etapa do processo. As tabelas a seguir mostram o modelo preenchido da aplicação da folha de verificação nas devidas etapas analisadas. Para melhor flexibilidade, o mês foi dividido em quinzenas, entretanto, a segunda possui um dia a mais devido a quantidade de dias que mês.

Tabela 6. Folha de Verificação Primeira Quinzena Outubro.

\begin{tabular}{|c|c|c|c|c|c|}
\hline \multicolumn{6}{|c|}{ FOLHA DE VERIFICAÇÃO - CHECK LIST } \\
\hline \multicolumn{3}{|c|}{ Localização: Produção } & \multicolumn{3}{|c|}{$\begin{array}{l}\text { Turno: } \\
\end{array}$} \\
\hline Data & Situação & $\begin{array}{c}\text { Entrada Inicial } \\
(\mathbf{k g})\end{array}$ & $\begin{array}{c}\text { Separação e Pesagem } \\
(\mathrm{kg})\end{array}$ & $\begin{array}{l}\text { Mistura e confecção } \\
\text { da massa }(\mathrm{kg})\end{array}$ & $\begin{array}{c}\text { Corte da } \\
\text { Massa (kg) } \\
\end{array}$ \\
\hline \multirow{2}{*}{$01 / 10 / 2018$} & Entrada & 298 & 298 & 281 & 398 \\
\hline & Saída & 298 & 281 & 398 & 365 \\
\hline \multirow{2}{*}{$02 / 10 / 2018$} & Entrada & 285 & 285 & 278 & 408 \\
\hline & Saída & 285 & 278 & 408 & 379 \\
\hline \multirow{2}{*}{$03 / 10 / 2018$} & Entrada & 298 & 298 & 289 & 424 \\
\hline & Saída & 298 & 289 & 424 & 389 \\
\hline \multirow{2}{*}{$04 / 10 / 2018$} & Entrada & 278 & 278 & 270 & 397 \\
\hline & Saída & 278 & 270 & 397 & 369 \\
\hline \multirow{2}{*}{$05 / 10 / 2018$} & Entrada & 285 & 285 & 268 & 394 \\
\hline & Saída & 285 & 268 & 394 & 361 \\
\hline \multirow{2}{*}{$06 / 10 / 2018$} & Entrada & 299 & 299 & 281 & 413 \\
\hline & Saída & 299 & 281 & 413 & 387 \\
\hline \multirow{2}{*}{ 07/10/2018 } & Entrada & 298 & 298 & 284 & 418 \\
\hline & Saída & 298 & 284 & 418 & 389 \\
\hline \multirow{2}{*}{ 08/10/2018 } & Entrada & 317 & 317 & 299 & 440 \\
\hline & Saída & 317 & 299 & 440 & 408 \\
\hline \multirow{2}{*}{ 09/10/2018 } & Entrada & 314 & 314 & 297 & 437 \\
\hline & Saída & 314 & 297 & 437 & 412 \\
\hline \multirow{2}{*}{$10 / 10 / 2018$} & Entrada & 313 & 313 & 302 & 445 \\
\hline & Saída & 313 & 302 & 445 & 417 \\
\hline \multirow{2}{*}{$11 / 10 / 2018$} & Entrada & 308 & 308 & 297 & 430 \\
\hline & Saída & 308 & 297 & 430 & 399 \\
\hline \multirow{2}{*}{$12 / 10 / 2018$} & Entrada & 294 & 294 & 280 & 410 \\
\hline & Saída & 294 & 280 & 410 & 379 \\
\hline \multirow{2}{*}{$13 / 10 / 2018$} & Entrada & 331 & 331 & 319 & 470 \\
\hline & Saída & 331 & 319 & 470 & 439 \\
\hline \multirow{2}{*}{$14 / 10 / 2018$} & Entrada & 284 & 284 & 274 & 403 \\
\hline & Saída & 284 & 274 & 403 & 375 \\
\hline \multirow{2}{*}{$15 / 10 / 2018$} & Entrada & 306 & 306 & 296 & 436 \\
\hline & Saída & 306 & 296 & 436 & 400 \\
\hline \multirow{2}{*}{$16 / 10 / 2018$} & Entrada & 332 & 332 & 327 & 465 \\
\hline & Saída & 332 & 327 & 465 & 439,9 \\
\hline \multirow{2}{*}{$17 / 10 / 2018$} & Entrada & 308 & 308 & 300 & 421 \\
\hline & Saída & 308 & 300 & 421 & 394,7 \\
\hline \multirow{2}{*}{$18 / 10 / 2018$} & Entrada & 318 & 318 & 310 & 440 \\
\hline & Saída & 318 & 310 & 440 & 413,3 \\
\hline
\end{tabular}


Citação (APA): Carvalho, F. L. S., de. \& Leite, C. P., Jr. (2022). Avaliação de perdas de matérias primas: uma proposta para melhoria no processo de uma panificadora. Brazilian Journal of Production Engineering, 8(2), 37-61.

\begin{tabular}{l|c|c|c|c|c} 
& & 316 & 308 & 430 \\
$\mathbf{1 9 / 1 0 / 2 0 1 8}$ & Entrada & 316 & 308 & 430 & 402 \\
& Saída & 316 & 313 & 305 & 427 \\
$\mathbf{2 0 / 1 0 / 2 0 1 8}$ & Entrada & 313 & 305 & 427 & 401 \\
& Saída & 313 & 289 & 280 & 400 \\
$\mathbf{2 1 / 1 0 / 2 0 1 8}$ & Entrada & 289 & 280 & 400 & 368 \\
& Saída & 289 & 279 & 270 & 390 \\
$\mathbf{2 2 / 1 0 / 2 0 1 8}$ & Entrada & 279 & 270 & 390 & 358 \\
& Saída & 279 & 305 & 297 & 413 \\
$\mathbf{2 3 / 1 0 / 2 0 1 8}$ & Entrada & 305 & 297 & 413 & 382 \\
& Saída & 305 & 296 & 290 & 400 \\
$\mathbf{2 4 / 1 0 / 2 0 1 8}$ & Entrada & 296 & 290 & 400 & 368 \\
& Saída & 296 & 296 & 289 & 393 \\
$\mathbf{2 5 / 1 0 / 2 0 1 8}$ & Entrada & 296 & 289 & 393 & 364 \\
& Saída & 296 & 297 & 287 & 390 \\
$\mathbf{2 6 / 1 0 / 2 0 1 8}$ & Entrada & 297 & 287 & 390 & 356 \\
& Saída & 296 & 303 & 298 & 367 \\
$\mathbf{2 7 / 1 0 / 2 0 1 8}$ & Entrada & 303 & 298 & 398 & 335,2 \\
& Saída & 303 & 328 & 320 & 430 \\
$\mathbf{2 8 / 1 0 / 2 0 1 8}$ & Entrada & 328 & 320 & 460 & 432 \\
& Saída & 328 & 329 & 312 & 406 \\
$\mathbf{2 9 / 1 0 / 2 0 1 8}$ & Entrada & 329 & 312 & 432 & 423 \\
& Saída & 329 & 310 & 300 & 440 \\
$\mathbf{3 0 / 1 0 / 2 0 1 8}$ & Entrada & 310 & 300 & 423 & 406,1 \\
\hline & Saída & 310 & 316 & 310 & \\
$\mathbf{3 1 / 1 0 / 2 0 1 8}$ & Entrada & 316 & 310 & 440 & \\
& Saída & 316 & & & \\
\hline
\end{tabular}

Fonte: Autores (2021).

Ao ser aplicado a Folha de Verificação, pode ser observado cada etapa do processo de forma distinta e pode ser observado o consumo dos recursos de acordo com as suas entradas em cada etapa. Dessa forma, pode-se mapear de forma mais precisa as entradas e saídas de cada etapa, mensurado e identificado as perdas relacionadas a cada parte do processo de acordo com as suas devidas saídas. Nesta análise, somente foi verificada as etapas de transformação dos recursos sendo elas: Separação e Pesagem, Mistura e Confecção da Massa, Modelagem da Massa e Corte da Massa.

Devido à falta da disponibilidade de tempo para a pesquisa, a ferramenta foi aplicada ao mês de outubro, no desenvolvimento da pesquisa a necessidade da aplicação da folha de verificação só se apresentou nesta etapa, assim, se restringe apenas ao mês de outubro de 2018 está devida analise da ferramenta. Após a aplicação foi identificado as perdas de acordo com as Tabelas 7 e 8 a seguir

Tabela 7. Folha de Verificação Resultado Primeira Quinzena Outubro

\begin{tabular}{c|c|c|c|c}
\hline \multicolumn{5}{|c}{ Perdas Primeira Quinzena Outubro } \\
\hline Dia & $\begin{array}{c}\text { Entrada } \\
\text { Inicial (kg) }\end{array}$ & $\begin{array}{c}\text { Separação e Pesagem } \\
(\mathbf{k g})\end{array}$ & $\begin{array}{c}\text { Mistura e confecção da massa } \\
(\mathbf{k g})\end{array}$ & $\begin{array}{c}\text { Corte da Massa } \\
(\mathbf{k g})\end{array}$ \\
\hline $\mathbf{0 1 / 1 0 / 2 0 1 8}$ & - & 8 & - & 32 \\
$\mathbf{0 2 / 1 0 / 2 0 1 8}$ & - & 13 & - & 28 \\
$\mathbf{0 3 / 1 0 / 2 0 1 8}$ & - & 9 & - & 35 \\
$\mathbf{0 4 / 1 0 / 2 0 1 8}$ & - & 15 & - & 27 \\
$\mathbf{0 5 / 1 0 / 2 0 1 8}$ & - & 13 & - & 33 \\
\hline
\end{tabular}


Citação (APA): Carvalho, F. L. S., de. \& Leite, C. P., Jr. (2022). Avaliação de perdas de matérias primas: uma proposta para melhoria no processo de uma panificadora. Brazilian Journal of Production Engineering, 8(2), 37-61.

\begin{tabular}{|c|c|c|c|c|}
\hline $06 / 10 / 2018$ & - & 8 & - & 26 \\
\hline 07/10/2018 & - & 18 & - & 29 \\
\hline 08/10/2018 & - & 16 & - & 31 \\
\hline 09/10/2018 & - & 7 & - & 25 \\
\hline $10 / 10 / 2018$ & - & 14 & - & 28 \\
\hline $11 / 10 / 2018$ & - & 7 & - & 26 \\
\hline $12 / 10 / 2018$ & - & 6 & - & 31 \\
\hline $13 / 10 / 2018$ & - & 8 & - & 28 \\
\hline $14 / 10 / 2018$ & - & 4 & - & 35 \\
\hline $15 / 10 / 2018$ & - & 6 & - & 28 \\
\hline $16 / 10 / 2018$ & - & 5 & - & 25,1 \\
\hline $17 / 10 / 2018$ & - & 8 & - & 26,3 \\
\hline $18 / 10 / 2018$ & - & 8 & - & 26,7 \\
\hline $19 / 10 / 2018$ & - & 8 & - & 28 \\
\hline $20 / 10 / 2018$ & - & 8 & - & 26 \\
\hline $21 / 10 / 2018$ & - & 9 & - & 32 \\
\hline $22 / 10 / 2018$ & - & 9 & - & 32 \\
\hline $23 / 10 / 2018$ & - & 8 & - & 31 \\
\hline $24 / 10 / 2018$ & - & 6 & - & 32 \\
\hline $25 / 10 / 2018$ & - & 7 & - & 29 \\
\hline $26 / 10 / 2018$ & - & 10 & - & 34 \\
\hline 27/10/2018 & - & 5 & - & 31,8 \\
\hline 28/10/2018 & - & 8 & - & 27 \\
\hline $29 / 10 / 2018$ & - & 17 & - & 26 \\
\hline $30 / 10 / 2018$ & - & 10 & - & 31,6 \\
\hline $31 / 10 / 2018$ & - & 6 & - & 33,9 \\
\hline $\begin{array}{l}\text { Total Perdas } \\
\text { (Kg) }\end{array}$ & & 132 & 0 & 472 \\
\hline
\end{tabular}

Fonte: Autores (2021).

A Tabela 9 mostram as perdas totais identificadas nos processos de Separação e no Processo de corte. As perdas em cada etapa no processo irão fornecer o quantitativo dos custos envolvidos, porém, serão contabilizados de forma geral na estimativa final.

É importante ressaltar que a perda no processo de corte é caracterizada como perda de material pré-fabricado dessa forma para ser encontrado a quantidade de trigo em cada dado registrado se faz necessário a observação da tabela 1 que mostra a participação em percentual do trigo. Dessa forma para o mês de outubro, no qual se apresentou necessário a aplicação desta ferramenta, tem-se a tabela a seguir com a devida mensuração e identificação total dos desperdícios para este mês.

Tabela 8. Resultado de Perdas Outubro

\begin{tabular}{c|c|c}
\hline \multicolumn{3}{|c}{ Perdas Outubro (kg) } \\
\hline Perda & Separação e Pesagem (kg) & Corte da Massa (kg) \\
\hline Material & 284 & 914 \\
\hline Total Trigo & \multicolumn{2}{|c}{1198} \\
\hline
\end{tabular}

Fonte: Autores (2021).

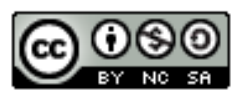



processo de uma panificadora. Brazilian Journal of Production Engineering, 8(2), 37-61.

\subsubsection{Resultados dos dados obtidos}

$\mathrm{Na}$ tabela abaixo é evidenciado os resultados observados relacionados a compra de trigo para a produção durante o período de análise produção, verificando as perdas de cada mês de acordo com as respectivas entradas.

Tabela 9. Compra Total de Trigo $(\mathrm{Kg})$

\begin{tabular}{c|r}
\hline \multicolumn{2}{c}{ Compra Mensal Total $(\mathbf{K g})$} \\
\hline Maio & 11145 \\
Junho & 10885 \\
Julho & 11155 \\
Agosto & 11130 \\
Setembro & 10840 \\
Outubro & 10850 \\
\hline
\end{tabular}

Fonte: Autores (2021).

Ainda, é importante compreender o consumo total relacionado a entrada de trigo no processo para isso a tabela a seguir nos fornece esses dados mostrados na Tabela 11

Tabela 10. Consumo Total de Trigo

\begin{tabular}{c|r}
\hline \multicolumn{2}{c}{ Consumo Mensal Total $(\mathbf{K g})$} \\
\hline Maio & 8833 \\
Junho & 8237 \\
Julho & 8721 \\
Agosto & 8887 \\
Setembro & 9025 \\
Outubro & 9439 \\
\hline
\end{tabular}

Fonte: Autores (2021).

Ainda, a entrada do trigo foi identificada as perdas no processo de forma clara na Tabela 12

Tabela 11. Perda Total Processo de Corte (continua)

\begin{tabular}{|c|c|}
\hline \multicolumn{2}{|c|}{ Perda Mensal Total $(\mathbf{K g})$} \\
\hline Maio & 1371,56 \\
Junho & 1538,84 \\
Julho & 1447,72 \\
Agosto & 1339,6 \\
Setembro & 1102,2 \\
Outubro & 1198,0 \\
\hline
\end{tabular}

Fonte: Autores (2021).

Para ser mensurado e entendido, o custo dessas perdas a Tabela 13 mostra a clareza do índice de desperdícios.

Tabela 12. Custo das Perdas Processo Corte

\begin{tabular}{c|c|}
\hline \multicolumn{2}{c}{ Custos de Perdas } \\
\hline Maio & $\mathrm{R} \$ 4.003,58$ \\
Junho & $\mathrm{R} \$ 4.491,87$ \\
Julho & $\mathrm{R} \$ 4.225,89$ \\
Agosto & $\mathrm{R} \$ 3.910,29$ \\
Setembro & $\mathrm{R} \$ 3.217,32$ \\
Outubro & $\mathrm{R} \$ 3.497,25$ \\
\hline \multicolumn{2}{c}{ Fonte: Autores $(2021)$}
\end{tabular}

Fonte: Autores (2021). 

processo de uma panificadora. Brazilian Journal of Production Engineering, 8(2), 37-61.

A tabela acima mostra somete o índice de custo de perda para a perda de material pré-fabricado já identificado. Porém, a pesquisa pode direcionar a identificação de mais perdas no processo produtivo, entretanto, por falta de disponibilidade de tempo, não será possível a localização das fontes de perdas dentro do processo, por outro lado será possível a proposta de monitoramento para futuramente a possível identificação e mensuração dos custos dessas perdas não identificadas.

\subsubsection{Estimativa de Receita perdida com as perdas de material}

Para mostra uma pequena estimativa do quanto a empresa deixou de faturar devido as perdas, a Tabela 14 abaixo deixa evidente

Tabela 14. Faturamento Perdido

\begin{tabular}{c|c|c|c|c}
\hline \multicolumn{2}{c|}{ Perda Mensal Total (kg) } & Peso médio pão francês $(\mathbf{k g})$ & Preço $($ un) & Total \\
\hline Maio & 1371,56 & 0,045 & $\mathrm{R} \$ 0,40$ & $\mathrm{R} \$ 12.069,73$ \\
Junho & 1538,84 & 0,045 & $\mathrm{R} \$ 0,40$ & $\mathrm{R} \$ 13.541,79$ \\
Julho & 1447,72 & 0,045 & $\mathrm{R} \$ 0,40$ & $\mathrm{R} \$ 12.739,94$ \\
Agosto & 1339,6 & 0,045 & $\mathrm{R} \$ 0,40$ & $\mathrm{R} \$ 11.788,48$ \\
Setembro & 1102,2 & 0,045 & $\mathrm{R} \$ 0,40$ & $\mathrm{R} \$ 9.699,36$ \\
Outubro & 1198,1 & 0,045 & $\mathrm{R} \$ 0,40$ & $\mathrm{R} \$ 10.543,28$ \\
\hline Total & $\mathbf{7 9 9 8 , 0 2}$ & $\mathbf{0 , 0 4 5}$ & $\mathbf{R} \mathbf{0 , 4 0}$ & $\mathbf{R} \mathbf{7 0 . 3 8 2 , 5 8}$ \\
\hline
\end{tabular}

Fonte: Autores (2021).

A Tabela 14 mostra a receita que a empresa poderia ter faturado caso houvesse aproveitado as devidas perdas de matérias primas. Durante o período analisado as perdas observadas foram de grande impacto na receita da empresa totalizando uma perda de receita de vendas de $\mathrm{R} \$$ $70.382,58$ no período de maio a outubro. Para a tentativa de minimizar essas perdas será proposto a empresa algumas alterações em seu processo produtivo e na forma de melhorar o aproveitamento das matérias primas desperdiçadas. Fica claro que o alto impacto na receita levanta a grande preocupação dos proprietários da empresa, visto que, conforme o item 4.3.1 deste presente estudo, apenas foi evidenciado as perdas de matérias primas no processo, caso este item tenha sido abrangente e englobado mais variáveis é possível que estas perdas poderiam causar mais impactos na receita final. Ainda, é valido ressaltar que esta receita é referente ao produto carro chefe da empresa e se considerarmos os custos de perdas esse prejuízo deve ser consideravelmente maior.

\subsection{Propostas para a Melhoria do Processo e Redução dos Custos Visando o Aumento da Receita}

Com base nos dados levantados e nos resultados das análises realizadas, constata-se que se faz necessário intervenção no processo. Desta forma pode-se propor ações para enfrentar as devidas perdas que causam prejuízos e perca de receita. Inicialmente se faz necessário observar o Mapeamento do Fluxo de Valor Atual conforme a figura 2 no tópico 4.3.2 deste presente estudo. Neste é notado que há etapas do processo que é grande o descarte de material pré-fabricados e que causa significativo custos para a empresa. Esses descartes promovem que as etapas subsequentes do processo não recebem a devida quantidade de entrada na mesma.

Ainda é importante mostrar que no atual processo os operados não seguem para a próxima etapa antes da atual ser realizada por completo o que caracteriza ociosidade de alguns trabalhadores

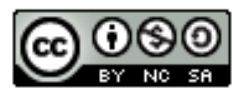



processo de uma panificadora. Brazilian Journal of Production Engineering, 8(2), 37-61.

e aumento no tempo de produção. Tal ociosidade tem a propensão de acarretar perdas no processo, visto que, a matéria prima pré-fabricada tem característica perecível.

Ainda, é importante observar a participação ativa de todos os funcionários em todas as etapas do processo considerando que em cada etapa há pelo menos oito funcionários presentes e que ainda há presença de ociosidade no processo.

Outro problema enfrentado na empresa se apresenta na falha de comunicação entre os responsáveis por todo o processo (os próprios proprietários) e pelo estoque (envolvendo a quantidade de matérias primas disponíveis), esta falha de comunicação pode ser custosa durante a realização do processo visto que esta também pode significar a eficiência e controle do processo. Por vezes a falta de comunicação permite a autonomia ao trabalhador podendo elevar o custo de matéria prima. Ainda ao analisar a figura 2, nota-se que os descartes no processo de corte tem sido fator de custos elevados e perda de receita.

Para o processo atual de acordo com o VSM mostrado na Figura 3, pode ser feito as alterações conforme a Figura 4 a seguir que mostra uma proposta de um estado futuro para o processo produtivo da empresa.

Figura 4. Mapeamento do Fluxo de Valor do Estado Modificado

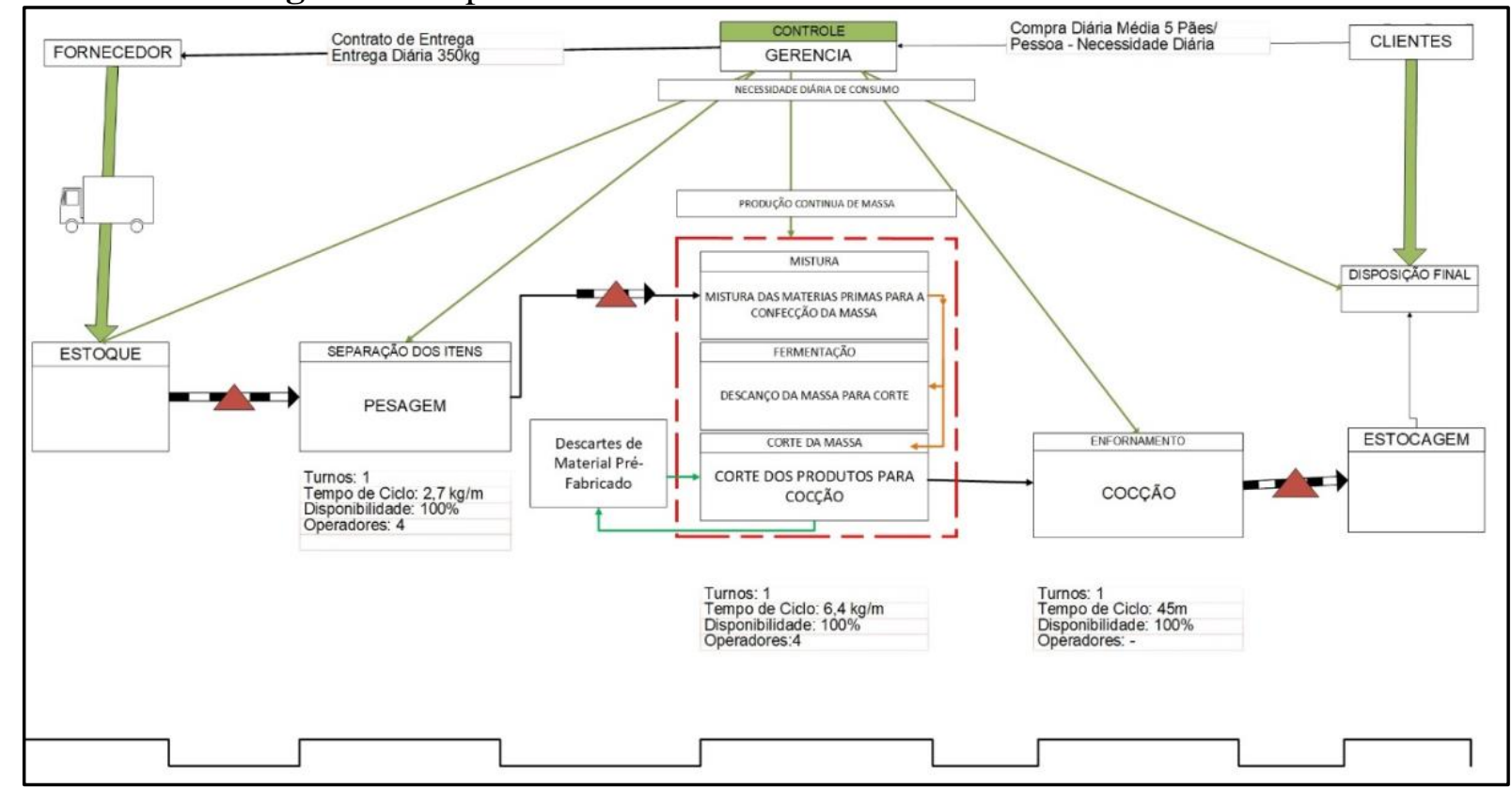

Fonte: Autores (2021).

\section{CONSIDERAÇÕES FINAIS}

Atualmente a forte concorrência existente entre as empresas dos mais diversos seguimentos gera a necessidade de gestores envolvidos na produção buscar formas e meios para o aumento da produtividade consequentemente tornando a empresa mais competitiva nas suas atividades de forma que esta busca não se torna um diferencial e sim uma maneira cíclica para que seja alcançado a excelência operacional de sobrevivência das organizações. Assim, o gerenciamento de processos e recursos tornou-se algo vital dentro das organizações quando se nota a necessidade de diminuir ou erradicar os prejuízos e custos envolvidos nos mesmos.

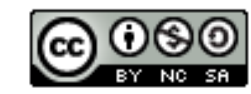



processo de uma panificadora. Brazilian Journal of Production Engineering, 8(2), 37-61.

Neste sentido, observa-se que o objetivo do trabalho de pesquisa foi alcançado, identificando as perdas juntamente com as suas devidas causas, não se limitando a isto, a pesquisa ainda contribuiu para que tais perdas fossem elencadas de acordo com as atividades inerentes ao processo quantificando e tratando cada perda de acordo com a necessidade para a devida etapa visando a redução dos prejuízos sejam estes de recursos ou de capital financeiro o que consequentemente pode favorecer a tomada de decisão da empresa em relação ao processo. Essas devidas observações durante a pesquisa realizada juntamente com a correta tomada de decisão dos proprietários podem trazer para a empresa um aumento significativo na competitividade e na redução dos prejuízos recorrentes se evitando riscos futuros para a organização.

Ainda, pode ser estimado que o profundo acompanhamento futuro do processo juntamente com as quantificações corretas das variáveis envolventes visando quantificar também os custos e prejuízos de outras etapas do mesmo, pode servir como base para o desenvolvimento e implantação de outras formas de melhorias durante o processo de fabricação, entretanto não se aplicando e se limitando para somente esta organização, mas também para futuras pesquisas no campo da Engenharia de Produção. Neste sentido, algumas ferramentas podem contribuir para a difusão e precisão dos resultados podendo ser elencada as Cartas de Controle de processo, uma vez que esta está propensa a fornecer dados de acompanhamento de processo de forma mais rápida e precisa o que pode ser fundamental para a mensuração de como está ocorrendo o processo.

A metodologia utilizada nesta pesquisa não é de complexo entendimento e pode ser difundida em diversas organizações independente do porte em que estas vierem a ter, com isso, pode ser gerado resultados precisos e importantes. Para a organização a pesquisa pode mostrar, quantificar e analisar os índices de consumo, as perdas e os prejuízos em que esta estava sofrendo devido à falta de acompanhamento do processo. Ao trazer estas analises para a realidade da empresa foi notado que era necessária a intermediação imediata das fontes de desperdícios e pode ser proposto melhorias nos processos conforme se observa no tópico de avaliação de resultados desta devida pesquisa, entretanto, ainda que a pesquisa pode contribuir com alguma proposta, a implantação ou a alteração de algum ponto no processo da empresa está inteiramente em responsabilidade dos proprietários, assim, não pode ser observado os resultados colhidos desta metodologia embora acredita-se sendo os melhores possíveis.

Por fim, a pesquisa proposta e realizada teve como base o conhecimento, quantificação e análise das etapas de um devido processo de produção do Pão de Sal apresentando os fatores que estavam influenciando nos gastos demasiados do processo. É compreensível que os desperdícios inerentes ao processo estejam presentes no cotidiano de produção de uma organização, mas, conhece-los, mensura-los e analisa-los é de responsabilidade das pessoas à frente da produção, neste sentido, a pesquisa pode trazer a vivencia e experiência de uma real situação onde a presença de um Engenheiro de Produção foi fundamental para a identificação de tais fatores sendo este uma peça ideal para a redução dos custos do processo com a aplicação de conhecimentos teóricos e práticos que foram adquiridos durante um longo período, desta forma, a pesquisa pôde também contribuir para a formação de profissionais da área de produção.

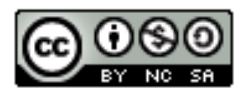


Citação (APA): Carvalho, F. L. S., de. \& Leite, C. P., Jr. (2022). Avaliação de perdas de matérias primas: uma proposta para melhoria no processo de uma panificadora. Brazilian Journal of Production Engineering, 8(2), 37-61.

\section{REFERÊNCIAS}

Associação Brasileira da Indústria de Panificação e Confeitaria. (2017). Indicadores 2016: Desempenho de Empresas de Panificação e Confeitaria Brasileiras em 2016. Brasília: ABIP. Recuperado de http://www.abip.org.br/site/wp-content/uploads/2017/02/INDICADORES2017-performance-2016.pdf

Associação Brasileira da Indústria de Panificação e Confeitaria. Recuperado de http://www.abip.org.br/site

Alvarez, M. E. B. (2016). Gestão de qualidade, Produção e Operações. $2^{\circ}$ ed. São Paulo: Atlas. Amorim, M. B. \& Rocha, A. C. B. (2012). Ferramentas de Engenharia de Produção para redução de desperdícios em cozinhas industriais. In: XXXII Encontro Nacional de Engenharia de Produção (Enegep) - Bento Gonçalves.

Bornia, A. C. (1995). Mensuração das perdas dos processos produtivos: uma abordagem metodológica de controle interno. Florianópolis: UFSC. Tese (Doutorado em Engenharia de Produção) PPGEP/UFSC

Brito, F. O. \& Dacol, S. (2008). A manufatura enxuta e a metodologia seis sigmas em uma indústria de alimentos. In: XXVIII Encontro Nacional de Engenharia de Produção (Enegep) Rio de Janeiro.

Cadioli, L. P. \& Perlatto, L. (2008). Mapeamento do fluxo de valor: uma ferramenta da produção enxuta. Anuário de produção acadêmica docente. 2(3).

Carpinetti, Luiz C. R. Gestão da qualidade: conceitos e técnicas. 2. ed. São Paulo: Atlas, 2012.

Carvalho, M. M. \& Paladini, E. P. (2005). Gestão da Qualidade: Teoria da Qualidade. Rio de Janeiro: Campos.

Carvalho, M. M. et al., (Org.). (2012). Gestão da Qualidade: Teoria e Casos. 2. ed. Rio de Janeiro: Elsevier.

Cervo, A. L. \& Bervian, P. A. (2002). Metodologia científica. 5.ed. São Paulo: Prentice Hall.

Crosby, P. B. (1997). Qualidade falando sério - perguntas que você sempre quis fazer sobre controle da qualidade. São Paulo: McGraW-Hill Ltda.

Feigenbaum, A. V. (1994). Controle da qualidade total. 1. ed. São Paulo: Makron Books.

Gadelha, G. R. de O. \& Morais, G. H. N. (2015). Análise do Processo de Desperdício de Embalagens em uma Indústria Alimentícia: Aplicação das Quatro Primeiras Etapas do MASP. Fortaleza - SC: XXXV ENEGEP.

Gaither, N. \& Frazier, G. (2002). Administração da produção e operações. São Paulo: Cengage Learning.

Gil, A. C. (2002). Como elaborar projetos de pesquisa. $4^{\mathrm{a}}$ Ed. São Paulo: Atlas.

Gil, A. C. (1999). Métodos e Técnicas de Pesquisa Social. 5.ed. São Paulo: Atlas.

Kirchnner, A., Fischer, G., Kaufmann, H., \& Schmid, D. (2009). Gestão da qualidade: Segurança do trabalho e gestão ambiental. 2. ed. São Paulo: Editora Blucher.

Liker, J. K. (2005). O modelo Toyota: 14 Princípios de gestão do maior fabricante do mundo. Porto Alegre: Bookman.

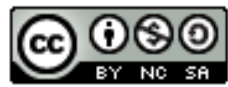



processo de uma panificadora. Brazilian Journal of Production Engineering, 8(2), 37-61.

Malik, A. M. \& Schiesari, L. M. C. (1998). Qualidade na gestão local de serviços e ações de saúde. São Paulo: Faculdade de Saúde Pública da USP.

Maximiano, A. C. A. (2011). Teoria geral da administração. 1. ed. São Paulo: Atlas.

Moreira, D. A. (2011). Administração da produção e operações. 2 ed. São Paulo: Cengage Learning.

Ohno, T. (1997). O Sistema Toyota de Produção: Além da produção em larga escala. Porto Alegre: Bookman.

Paladini, E. P. (2005). Perspectiva estratégica da qualidade. In: Carvalho, M. M. \& Paladini, E. P. (Coords.). Gestão da Qualidade: Teoria e casos. Rio de Janeiro: Elsevier, p.23-84.

Peinado, J. \& Graeml, A. R. (2007). Administração da produção: operações industriais e de serviços. Curitiba: UnicenP.

Rother, M. \& Shook, J. (2003). Aprendendo a enxergar: Mapeando o fluxo de valor para agregar valor e eliminar o desperdício. São Paulo: Lean Institute Brasil.

Santos, D. (2016). Análise de perdas no processo produtivo: Estudo de caso realizado em uma indústria de palmito. 93 f. Graduação em Engenharia Industrial. Universidade Federal do Pará, Abaetetuba.

Schappo, R. T. M. (2007). Estudo e Análise da Implantação da Filosofia de Produção Enxuta (Lean Production). Monografia. Itajaí. Universidade de Engenharia Industrial Mecânica. Universidade do Vale do Itajaí.

Shingo, S. (1996). O Sistema Toyota de Produção do ponto de vista da Engenharia de Produção. 2. Ed. Porto Alegre: Bookmark.

Silva, E. L. \& Menezes, E. M. (2001). Metodologia da pesquisa e elaboração de dissertação. 3. ed. Florianópolis: Laboratório de Ensino a Distância da UFSC.

Toledo, J. C., de., et al., (2014). Qualidade: Gestão e Métodos. Rio de Janeiro: LTC. 397 p. ISBN 9788521621171

Werkema, M. C. C. (2006). Ferramentas Estatísticas Básicas para o Gerenciamento de Processos. Vol 1 e 2. ed. Belo Horizonte.

Womack, James P.; JONES, Daniel T. A mentalidade enxuta nas empresas. 2. ed. Porto Alegre: Bookman, 2004.

Vieira, S. (1999). Estatística para a qualidade: como avaliar com precisão a qualidade em produtos e serviços. Rio de Janeiro: Campus. 